\title{
Assimilation of sea surface temperature into CECOM by flux correction
}

\author{
Yongsheng Wu • Charles Tang • Ewa Dunlap
}

Received: 31 July 2009 / Accepted: 17 January 2010 / Published online: 25 February 2010

(C) The Author(s) 2010. This article is published with open access at Springerlink.com

\begin{abstract}
Sea surface temperature (SST) from a near realtime data set produced from satellites data has been assimilated into a coupled ice-ocean forecasting model (Canadian East Coast Ocean Model) using an efficient data assimilation method. The method is based on an optimal interpolation scheme by which SST is melded into the model through the adjustment of surface heat flux. The magnitude and space-time variation of the adjustment depend on the depth of heat diffusion into the water column in response to changes in surface flux, the correlation time scale of the data, and model and data errors. The diffusion depth is scaled by the eddy diffusivity for temperature. The ratio of the model and data errors is treated as an adjustable parameter. To evaluate the quality of the assimilation, the results from the model with and without assimilation are compared to independent ship data from the Atlantic Zone Monitoring Program and the World Ocean Circulation Experiment. It is shown that the assimilation has a significant impact on the modeled SST, reducing the root mean square difference (RMSD) between the model SST and the ship SST by $0.63^{\circ} \mathrm{C}$ or $37 \%$. The RMSD of the assimilated SST is smaller than that of the satellite SST by $0.23^{\circ} \mathrm{C}$. This suggests that model simulations or predictions with data assimilation can provide the best estimate of the true SST. A sensitivity study is performed to examine the change of the model RMSD with the adjustable parameter in the assimilation equation. The results show that there is an optimal value of the
\end{abstract}

Responsible Editor: Tal Ezer

Y. Wu $\cdot$ C. Tang $(\triangle) \cdot$ E. Dunlap

Ocean Sciences Division, Bedford Institute of Oceanography,

Fisheries and Oceans Canada,

Dartmouth, Nova Scotia B2Y 4A2, Canada

e-mail: Charles.Tang@mar.dfo-mpo.gc.ca parameter and the model SST is not very sensitive to the parameter.

Keywords Data assimilation · Forecast model · Sea surface temperature $\cdot$ Heat flux correction $\cdot$ Heat diffusion depth

\section{Introduction}

With the advent of remotely sensed data (e.g., sea surface temperature [SST] and sea surface height), data assimilation has been successfully implemented in many ocean models and has proved to be a powerful tool to reduce the uncertainties of the models (Mellor and Ezer 1991; Ezer and Mellor 1994, 1997; Aikman et al. 1996; Horton et al. 1997; Carton et al. 2000; Kelley et al. 2002).

Previous studies have shown that the assimilation of SST into an ocean model can be accomplished in two ways. The first is to correct the model SST using observations, usually satellite-derived SST, immediately after the model integration by various assimilation schemes such as optimal interpolation, Kalman filter, and 3-D variational assimilation. This method is straightforward, which forces the model SST to approach the satellite SST. Since the correction is only applied to the uppermost layer of the model, an additional correction to the deep layers is needed to maintain dynamical consistency between the corrected SST and the model equations (Pinardi et al. 1995; Ezer and Mellor 1997). In the second method, the influence of satellite SST on model SST is realized through the adjustment of surface heat flux. This method is commonly used in multiyear model runs to eliminate the long-term shift of model SST (Barnier 1998; Rochford et al. 2001; Covey et al. 2003; Wu et al. 2007). The SST is treated as an integral component of the model. The redistribution of heat within the water column is 
controlled by the dynamic processes of the ocean model. However, the change of SST due to the adjustment is not known until the temperature equation is solved. This means that the relationship between the given heat flux and the expected change of SST is implicit. This also implies that the change of SST is not only related to the amount of the heat flux but also to the physical processes of the upper ocean, such as vertical mixing, stratification, and horizontal advection and diffusion. If the contribution from the horizontal processes is negligible, the redistribution of heat is controlled by two opposing processes, vertical mixing and stratification. The involvement of the physical processes suggests that, for a prescribed SST change, the estimation of the adjusted heat flux requires information on the properties of the water column.

In this paper, by adjusting surface heat flux, we assimilate near real-time SST from satellites into a forecasting model with the aim to improve the forecast skill of the model. Our emphasis is the determination of the magnitude and time-space variability of the heat flux correction. The assimilation scheme is based on optimal interpolation. Compared to more advanced schemes such as Kalman filter and 3-D variational assimilation, optimal interpolation is mathematically simpler and computationally more efficient (Carton et al. 2000).

In the flux correction method, SST change is realized through heat flux. As a consequence, the influence of the assimilation is felt only in the upper ocean where the temperature is controlled by heat transfer processes. SST change due to other dynamical processes such as hydrodynamic instability and generation of topographic waves cannot be handled by this method in a dynamically consistent way. A procedure to project changes of surface SST into the deep ocean is required. For this reason, the method we develop here is applied only to the shelf regions off the east coast of Canada and the central and northern Labrador Sea where SST is mainly controlled by atmospheric forcing and the upper ocean dynamics. These are the priority areas for ocean forecasting in eastern Canada. SST in the Gulf Stream region and its extension and the Newfoundland Basin will not be discussed in this paper.

\section{Method of SST data assimilation}

The flux correction method for SST data assimilation has the following general form:

$Q_{\text {net }}=Q+\lambda \times\left(T^{\mathrm{m}}-T^{\mathrm{o}}\right)$

where $Q_{\text {net }}$ is the total heat flux and $Q$ is the first-guess heat flux, which can be either heat flux calculated from satellite SST and atmospheric variables or model heat flux at the previous time step. Heat flux from ocean to atmosphere is defined as positive and from atmosphere to ocean is defined as negative. $T^{\mathrm{o}}$ and $T^{\mathrm{m}}$ are satellite and model SST, respectively. The second term on the right-hand side of Eq. 1 is a feedback term which modifies the heat flux in such a way that, if the model SST is higher (lower) than the satellite SST, the heat flux is increased (decreased) to cool (heat) the water. $\lambda$ is a coefficient which controls the magnitude of the correction.

Several forms for the coefficient $\lambda$ have been proposed, including constant and $\lambda=\partial Q / \partial T^{\circ}$ (Ezer and Mellor 1992; Barnier 1998). In this study, an expression based on the optimal interpolation theory as summarized in Mellor and Ezer (1991) will be derived for $\lambda$.

Consider the model SST, $T_{i}^{\mathrm{m}}$, at a model time and grid point denoted by the subscript $i$, is corrected to yield an improved SST, $T_{i}^{\mathrm{a}}$, according to:

$$
T_{i}^{\mathrm{a}}=T_{i}^{\mathrm{m}}+\sum_{\alpha=1}^{N} P_{i \alpha}\left(T_{\alpha}^{\mathrm{o}}-T_{\alpha}^{\mathrm{m}}\right)
$$

where $T_{\alpha}^{\mathrm{o}}$ is the satellite SST and $T_{\alpha}^{\mathrm{m}}$ is the model SST at the time and location of the satellite data denoted by the subscript $\alpha . N$ is the number of data sets to be included in the interpolation. $P_{i \alpha}$ are weights obtained by minimizing the difference between the model prediction and the satellite data, which are solutions of a set of algebraic equations involving the error matrices for the model and satellite SST (Mellor and Ezer 1991). The error matrices can be parameterized by Gaussian or exponential functions in time and space. Since the horizontal correlation scale of the SST field, $100 \mathrm{~km}$ from a correlation analysis of the satellite data, is much greater than the model grid size, $10 \mathrm{~km}$, the spatial part of the error matrices will be neglected and only the temporal part is kept in the matrices.

In this study, data assimilation is performed in the forecast mode. The most recent satellite data have the dominant influence on the model. Therefore, we set $\alpha=1$ and Eq. 2 is reduced to:

$T^{\mathrm{a}}=T^{\mathrm{m}}+\frac{\varepsilon_{\mathrm{m}}^{2}}{\varepsilon_{\mathrm{m}}^{2}+\varepsilon_{\mathrm{o}}^{2}} \exp \left[-\frac{\left(t-t_{1}\right)^{2}}{2 \tau^{2}}\right]\left(T_{1}^{\mathrm{o}}-T_{1}^{\mathrm{m}}\right)$

where the subscript $i$ has been removed for clarity. The time $t$ is the model time. $\tau$ is the time scale of the SST field. The subscript " 1 " denotes the time of the most recent satellite data $\left(t_{1} \leq t\right) . \varepsilon_{\mathrm{m}}$ and $\varepsilon_{\mathrm{o}}$ represent model and data errors, respectively. The model errors include errors in atmospheric data, bulk formulas for fluxes, boundary conditions, temperature-salinity fields, model physics and parameters, topography, and numerical scheme. The data errors may include instrumental errors, atmospheric corrections, and errors in the processing algorithms. An estimation of these errors is beyond the scope of this investigation. 
To relate SST to heat flux, we consider a heat flux perturbation applied at the ocean surface, $\Delta Q$, over time $t_{\mathrm{d}}$. The perturbation will cause cooling or heating of a water column of depth $h$. The change of the water temperature, $\Delta T$, is related to $\Delta Q$ by:

$$
\Delta T=-\frac{t_{\mathrm{d}}}{\rho c_{\mathrm{p}} h} \Delta Q
$$

where $\rho$ is the water density and $c_{\mathrm{p}}$ is the specific heat of water. Expressing the first terms on each sides of Eq. 3 in terms of heat flux using Eq. 4, we have:

$Q^{\mathrm{a}}(t)=Q^{\mathrm{m}}(t)+\gamma\left[T^{\mathrm{m}}\left(t_{1}\right)-T^{\mathrm{o}}\left(t_{1}\right)\right]$,

$\gamma=\frac{\rho c_{\mathrm{p}} h}{t_{\mathrm{d}}} F \exp \left[-\frac{\left(t-t_{1}\right)^{2}}{2 \tau^{2}}\right]$

where $F=1 /\left[1+\left(\varepsilon_{\mathrm{o}} / \varepsilon_{\mathrm{m}}\right)^{2}\right] . F$ ranges from 0 to 1 . The depth at which the temperature change can reach, $h$, is unknown. However, its order of magnitude and variation with the season and geographic location can be obtained from the temperature equation:

$\frac{\partial T}{\partial t}=\ldots \ldots+\frac{\partial}{\partial z}\left(k_{\mathrm{m}} \frac{\partial T}{\partial z}\right)$.

From a scale analysis of Eq. 7, the depth scale, $\Delta z$, is found to be related to the time scale, $\Delta t$, by $\Delta z \sim\left(k_{\mathrm{m}} \cdot t_{\mathrm{d}}\right)^{\frac{1}{2}}$ where $k_{\mathrm{m}}$ is the vertical eddy diffusion coefficient. $\Delta z$ can be identified as $h$ and $\Delta t$ as $t_{\mathrm{d}}$. The relation between $h$ and $t_{\mathrm{d}}$ is:

$h=A\left(k_{\mathrm{m}} \cdot t_{\mathrm{d}}\right)^{\frac{1}{2}} \equiv A h_{0}$

where $A$ is proportionally constant. $k_{m}$ can be obtained from the model. $t_{\mathrm{d}}$ is the time interval of satellite data. We shall call $h_{0}$ the diffusion depth since it is the depth scale of the heat diffusion Eq. 7. Combing $A$ and $F$, we have:

$F^{\prime}=A F=A /\left[1+\left(\varepsilon_{\mathrm{o}} / \varepsilon_{\mathrm{m}}\right)^{2}\right]$,

$\gamma=\frac{\rho c_{\mathrm{p}} h_{0}}{t_{\mathrm{d}}} F^{\prime} \exp \left[-\frac{\left(t-t_{1}\right)^{2}}{2 \tau^{2}}\right]$.

Equations 5 and 10 are the equations for the SST data assimilation in this study. Equation 5 is an improvement over Eq. 1. The temporal and spatial variation of the correction term in Eq. 5 can be partially determined from the model. However, the ratio of the data and model errors and the magnitude of $h$ are still undetermined. Our approach is to assume $F^{\prime}$ a constant. A range of values for $F^{\prime}$ will be used in a series of data assimilation experiments. The results will be evaluated against an independent in situ SST data set to determine the optimal $F^{\prime}$. The robustness of the assimilation to $F^{\prime}$ will then be investigated in a sensitivity study in Section 8 .

\section{The ocean model}

The model used in this study is the Canadian East Coast Ocean Model (CECOM) developed at Bedford Institute of Oceanography for ocean forecasting, coastal circulation, and sea ice studies. It is a coupled ice-ocean model. The ocean component of the model is the latest version of the Princeton Ocean Model (Blumberg and Mellor 1987). The ice component is a multicategory sea ice model. A full description of the ice model can be found in Yao et al. (2000) and Tang et al. (2008).

The model domain extends from the north end of Baffin Bay to the northern wall of the Gulf Stream and from the St. Lawrence Estuary to $42^{\circ} \mathrm{W}$ (Fig. 1). The resolution of the model is $0.1 \times 0.1^{\circ}$ on a rotated spherical coordinate system. The equator of the rotated earth runs through the middle of the Labrador Sea in the north-south direction. The vertical coordinate is the generalized $\sigma$-coordinate developed by Mellor et al. (2002). It allows both the $z$ and the $\sigma$ levels in the vertical direction. In CECOM, the vertical levels are selected according to the bottom depth. For bottom depth

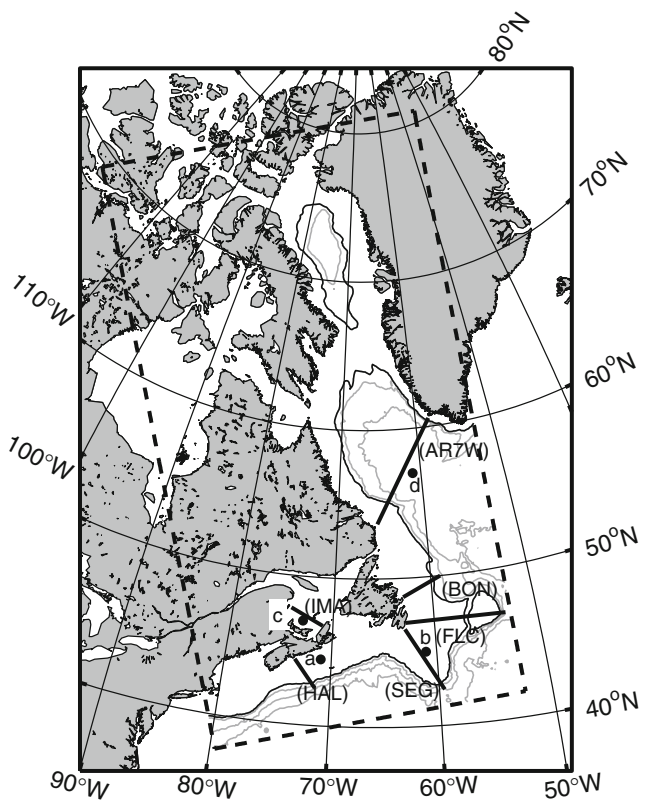

Fig. 1 The model domain is indicated by the box. Depth contours for 1,000 to $4,000 \mathrm{~m}$ with an interval of $1,000 \mathrm{~m}$ (in black) are shown. The black lines are SST sections of AZMP and WOCE. AR7W Labrador Sea, BON Bonavista line, FLC Flemish Pass line, SEG southeast Grand Banks, HAL Halifax line, IMA Îles-de-la-Madeleine. The solid circles are selected sites for analysis: $a$ Scotia Shelf, $b$ Gulf of St. Lawrence, $c$ Grand Banks, $d$ Central Labrador Sea 
$\geq 640 \mathrm{~m}$, a fixed upper layer of $64 \mathrm{~m}$ with eight levels and the underlying ocean with 13 levels are specified. The levels are scaled according to the thickness of the fixed upper layer or the varying lower layer. For bottom depth $\leq 10 \mathrm{~m}$, all levels are distributed uniformly. For bottom depth between 10 and $640 \mathrm{~m}$, the levels are linearly interpolated between the levels for 10 and $640 \mathrm{~m}$. The open boundaries are set using the flow relaxation scheme of Martinsen and Engedahl (1987). The details of the boundary set up can be found in Yao et al. (2000) and Tang et al. (2008).

\section{SST data}

SST data used in the assimilation are from a near real-time operational data set produced by Canadian Meteorological Centre (CMC; hereafter referred to as satellite SST). The data set is compiled from three kinds of remotely sensed SST and released daily with a resolution of $1 / 3^{\circ}$ on the global scale. A detailed description of the method of processing and validation can be found in Brasnett (2008). In this study, the data are linearly interpolated into the model grid. The quality of the data has been evaluated by Wu et al. (2009) using an independent in situ SST data set from the Atlantic Zone Monitoring Program (AZMP). The result shows that, on the regional scale, the satellite SST is well correlated to the in situ SST, but appreciable differences between the two are found in the shelf break areas (Wu et al. 2009).

\section{Implementation of the assimilation scheme}

To assess the skill of the data assimilation scheme outlined in Section 2, we compare the model SST from two simulations for 2007 , one with and the other without data assimilation. The two simulations started from the same initial state. The initial state was obtained in two steps. Firstly, the model was run for 5 years using the North American Regional Reanalysis monthly climatology (http:// www.emc.ncep.noaa.gov/mmb/rreanl/index.html) to obtain a stable ocean. The initial temperature and salinity fields used in the spin up run are high-resolution monthly temperature and salinity climatologies obtained from an objective analysis of historical temperature and salinity data archived at BIO dating back to 1910 (Tang 2007).

The model was then run for 15 months from 15 September 2005 to 31 December 2006 forced by three-hourly surface fluxes calculated from the atmospheric parameters in CMC's weather forecast model. The parameters include surface wind, air temperature, dew point temperature, relative humidity, precipitation, and cloud fraction.

Using the 31 December 2006 ocean as the initial state, the model was run separately with and without SST data assimilation for the entire 2007 in a simulated forecast mode. This means that, at the model time $t$, no satellite SST is available except at the time of the satellite data. The SST to be assimilated into the model is the latest available (i.e., within $24 \mathrm{~h}$ ) satellite SST. In a data assimilation run, in order to reduce noise in the output, $T^{\mathrm{m}}\left(t_{1}\right)$ in Eq. 5 was replaced by the averaged SST of the past $24 \mathrm{~h}$. The value did not change until new satellite SST data became available.

The Labrador/Newfoundland coastal waters and Baffin Bay are covered by sea ice in winter. As CECOM is a coupled ice-ocean model, sea ice was generated from the model runs. But for the purpose of this study, the SST assimilation is only applied to ice free waters.

The satellite SST is available once a day and hence $t_{\mathrm{d}}=$ 1 day in Eq. 10. The time scale of the SST field, $\tau$ in Eq. 10, was obtained from a correlation analysis of the data. The mean value is 1 day. $F^{\prime}$ is set to 0.1 . This value corresponds to the minimum root mean square difference (RMSD) between the model and ship SSTs. A detailed discussion of the sensitivity of model results to $F^{\prime}$ will be given in Section 8 . The diffusion depth, $h_{0}$, was obtained by averaging $k_{\mathrm{m}}$ from a separate multiyear model run over the mixed layer depth for each month. The mixed layer depth was determined from the monthly temperature and salinity data (Tang 2007) and a density difference criterion of $0.07 \mathrm{~kg} \mathrm{~m}^{-3}$. The procedure produced a monthly $h_{0}$ climatology which can be used in future work of SST assimilation. $h_{0}$ for four selected months are plotted in Fig. 2, which shows that the diffusion depth has a large range, 10 to $400 \mathrm{~m}$, and strongly seasonal and spatial variability. Diffusion of heat in the upper layer is mainly related to two opposite processes. One is wind mixing which acts to increase the diffusion depth. The other is thermal stratification which acts to decrease the diffusion depth. In spring, with the increasing solar heating and diminishing winds, the diffusion depth decreases significantly from the winter values. A minimum is reached in summer. In fall, with the decreasing solar heating and increasing winds, the diffusion depth starts to increase and reaches a maximum in winter. Horizontally, the diffusion depth in coastal waters is generally shallower than that in open waters. However, a belt of shallow diffusion depth can be seen along the shelf break. This is related to strong vertical stratification in the Labrador Current.

\section{Comparison of model SST with and without data assimilation}

In this section, we compare the model SST for 2007 between the simulations with and without data assimilation using daily averaged model output. The comparison allows 
Fig. 2 Diffusion depth $h_{0}$ (in meters) for February, May, August, and November
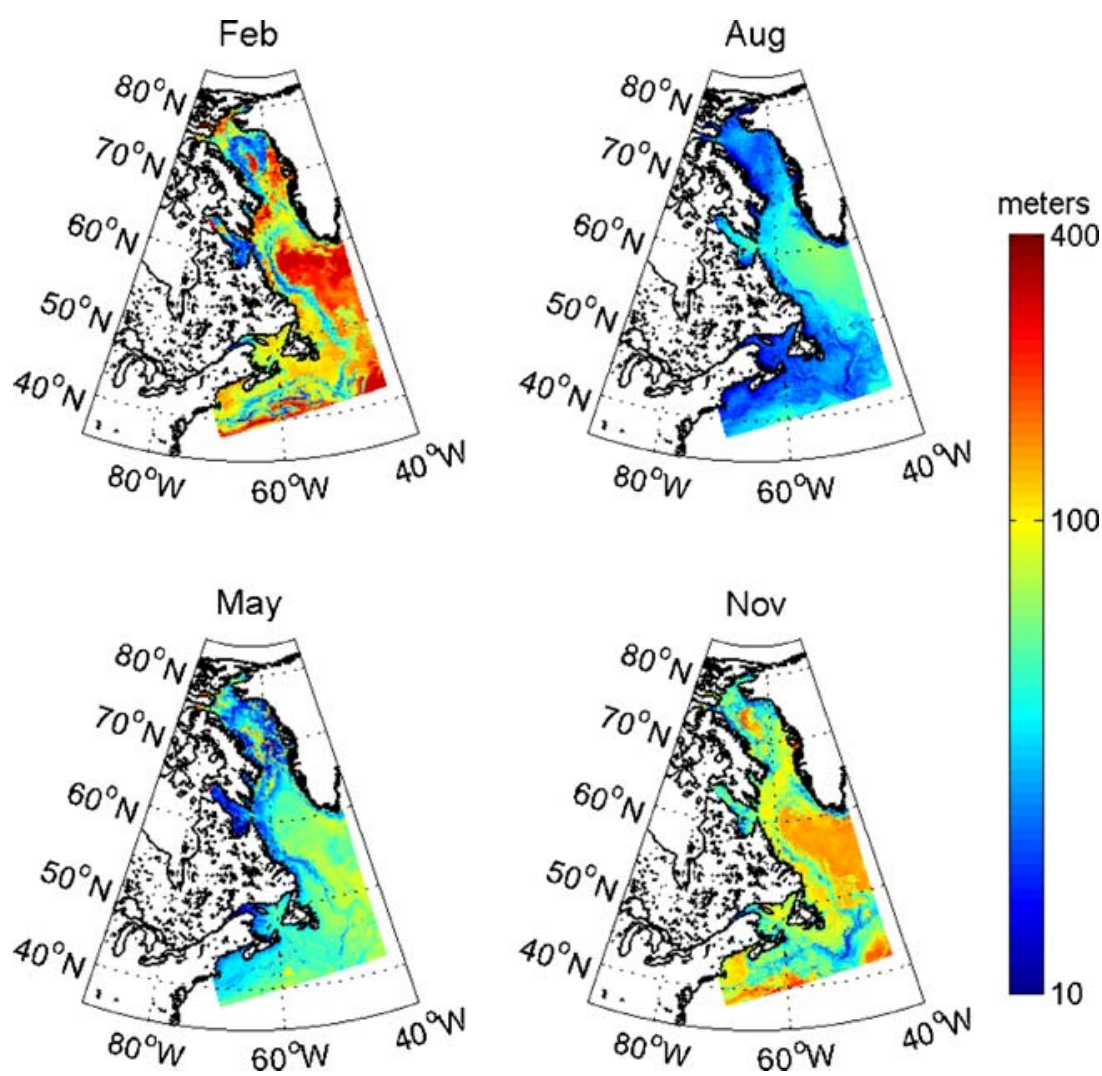

us to examine the impact of the assimilation on the model SST. We note that the satellite SST used in the data assimilation is not the true SST, but a best estimate based on satellite data calibrated by in situ SST. A good agreement between the model and satellite SSTs does not necessarily mean that the best estimate of the true SST is obtained because there are errors in the satellite SST as noted in Section 2. The comparison carried out in this section can help to assess the efficiency of the assimilation scheme. The skill of the data assimilation can only be evaluated when the model SST is compared to independent in situ SST. This will be carried out in the following section.

Comparisons of SST time series at selected locations are presented first followed by comparisons on the horizontal plane. The four selected locations (see Fig. 1) represent the Scotia Shelf, the Grand Banks, the Gulf of St. Lawrence, and the Central Labrador Sea. In general, the model SST without data assimilation is too high except for the Grand Banks and the Gulf of St. Lawrence in spring. The data assimilation lowers the temperature by increasing the ocean-to-atmosphere heat flux. The resulting SST is closer to the satellite SST than the model SST without data assimilation for all the locations (Fig. 3). At the shelf locations, the difference between the model SST and the satellite SST is smaller in summer than that in other seasons.
In Fig. 4, the satellite SST and model-data differences are shown. In the model SST without assimilation, the greatest SST difference is found in the open ocean and slope water off Newfoundland. In comparison to the satellite SST, the model SST in the Labrador Sea is too warm by $2.5^{\circ} \mathrm{C}$. The SST difference over the shelves is smaller. The SST difference from the model with data assimilation (middle panels) is in general smaller than that from the model without data assimilation (right panel). This indicates the data assimilation improves the model SST.

Along the edge of the Labrador shelf where the Labrador Current flows, little difference is found between the model SSTs with and without data assimilation. However, both are cooler than the satellite SST by $2^{\circ} \mathrm{C}$. The explanation for these results is that the satellite SST is too smooth, giving an unrealistic SST distribution in the Labrador Current along the shelf edge. The model can correct for the errors in the satellite SST. The errors have been analyzed by $\mathrm{Wu}$ et al. (2009) who found that the satellite SST was warmer than in situ SST by $2-3^{\circ} \mathrm{C}$ in the shelf break area.

Statistics for the satellite and model SSTs averaged over the study area (Fig. 4) for each month are given in Table 1. Without data assimilation, the model overpredicts SST in the summer months and underpredicts SST in the winter months. The largest biases are $0.75^{\circ} \mathrm{C}$ for July and $0.55^{\circ} \mathrm{C}$ for August. After data assimilation, the bias is reduced for all months. The July and August biases are $0.22^{\circ} \mathrm{C}$ and 

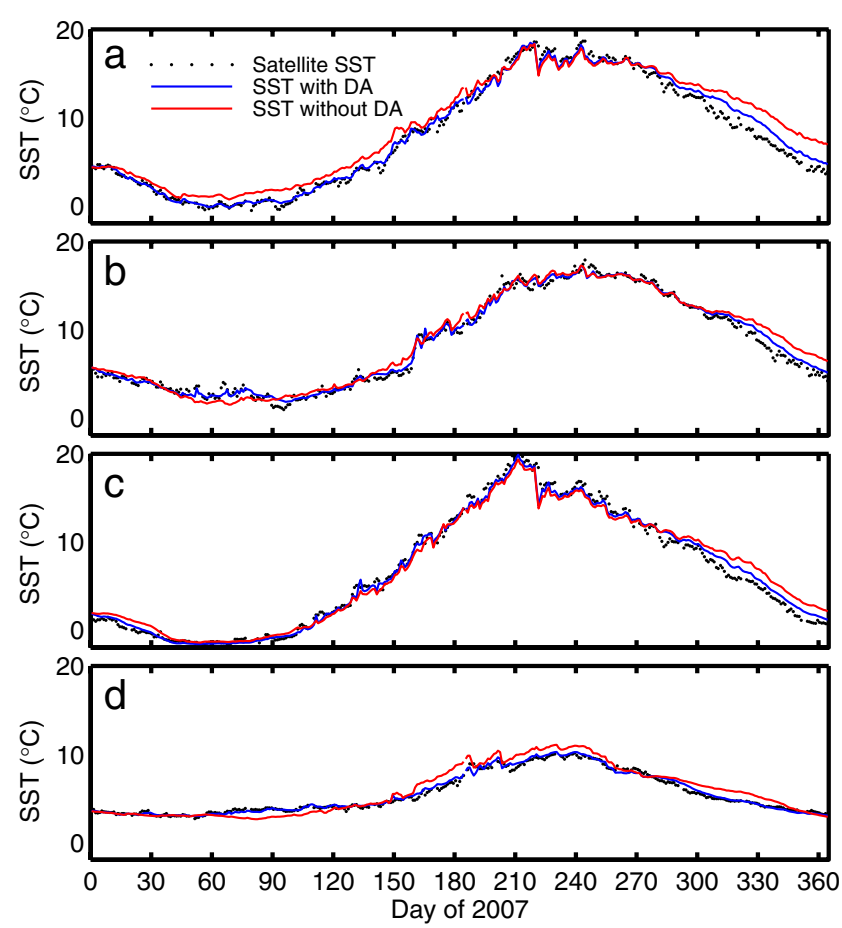

Fig. 3 Comparisons of SST time series from satellite and model with and without data assimilation $(D A)$. From top to bottom, the four panels represent four locations on a Scotia Shelf, b Grand Banks, c Gulf of St. Lawrence, and d Central Labrador Sea (see Fig. 1 for location)

$0.08^{\circ} \mathrm{C}$, respectively. The model RMSDs after data assimilation are smaller than those without data assimilation for all months. The 12 -month mean RMSD is $1.16^{\circ} \mathrm{C}$ without data assimilation and $0.728^{\circ} \mathrm{C}$ after data assimilation. These figures represent a significant improvement by data assimilation.

The monthly mean heat fluxes averaged over the study area with and without data assimilation are presented in Table 2. The difference ranges from $1 \mathrm{~W} \mathrm{~m}^{-2}$ (February and August) to $14 \mathrm{~W} \mathrm{~m}^{-2}$ (April and October). The relatively large difference for spring (March-May) and fall (October) may be related to the rapid change in SST and mixed layer depth in these periods.

The coefficient of the flux correction term, $\gamma$, is large in winter and small in summer (Table 2). The minimum is $123 \mathrm{~W} \mathrm{~m}^{-2} \mathrm{~K}^{-1}$ (July) and the maximum is $534 \mathrm{~W} \mathrm{~m}^{-2} \mathrm{~K}^{-1}$ (February). The seasonal variation reflects the seasonal change in the diffusion depth.

\section{Evaluation of the assimilated SST}

To evaluate the quality of the assimilated SST, we compare the model results with and without data assimilation with independent in situ data. The in situ temperature is from ship measurements along several sections of the AZMP (http://www.meds-sdmm.dfo-mpo.gc.ca/isdm-gdsi/azmppmza/index-eng.html) and the World Ocean Circulation Experiment (WOCE). From north to south (see Fig. 1), the sections are Labrador Sea (AR7W), Bonavista (BON), Flemish Cap (FLC), South East Grand Banks (SEG), Îlesde-la-Madeleine (IMA), and Halifax line (HAL).

The main goal here is to investigate whether the data assimilation can reduce the uncertainty/error of the model. The uncertainty is defined as the deviation of the model SST from the in situ SST. The uncertainty in the satellite SST will also be examined and compared to the model error. The model SST with and without data assimilation and satellite and in situ SSTs across the five AZMP sections from the 2007 spring (left panels) and fall (right panels) cruises are shown in Fig. 5.

From the figure, we can draw two general conclusions. (a) The model SST with assimilation is better than that without assimilation. The best examples are HAL in spring and BON in fall. The model SST without assimilation overpredicts the SST by up to $5^{\circ} \mathrm{C}$. The data assimilation lowers the SST and brings it closer to the in situ and satellite SST. (b) Where and when the satellite SST has relatively large errors, for example, FLC at $400 \mathrm{~km}$ and
Fig. 4 SST and SST difference between model and satellite SSTs for summer. From left to right, the maps are satellite SST, model SST with data assimilation minus satellite SST, and model SST without data assimilation minus satellite SST. The color bar is for the middle and right panels only
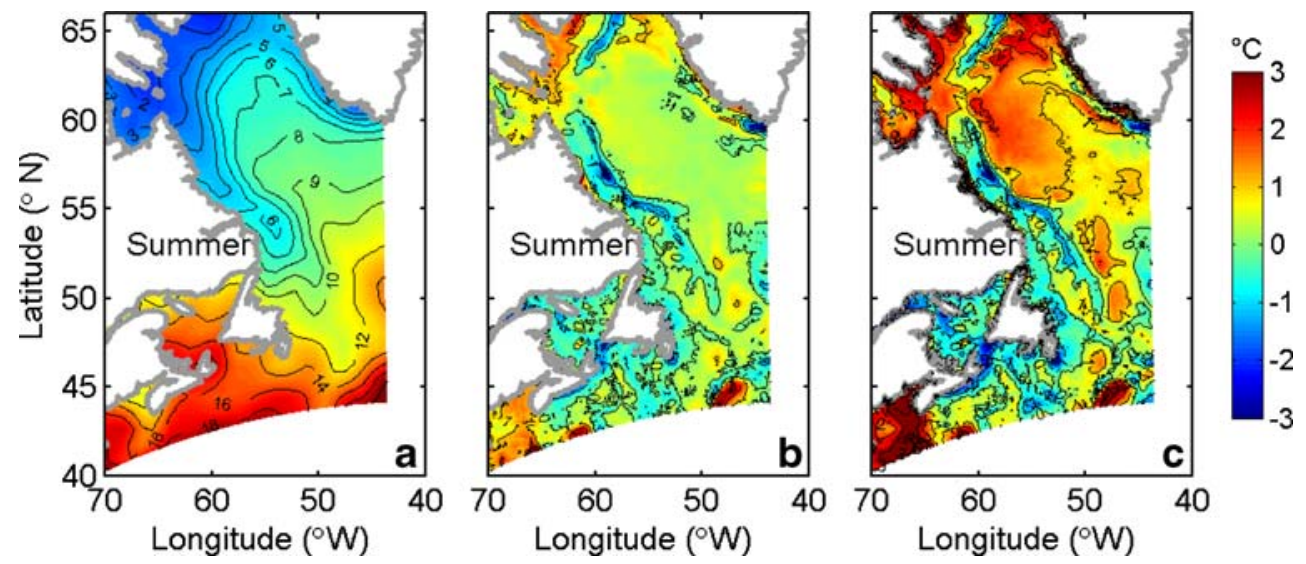
Table 1 Monthly mean SST, bias, and RMSD between satellite SST and model SST with (DA) and without (ND) data assimilation

\begin{tabular}{lcrrrrrrrrrrrrr}
\hline & & Jan. & Feb. & March & April & May & June & July & Aug. & Sep. & Oct. & Nov. & Dec. & Mean \\
\hline Data & & 2.13 & 1.54 & 1.50 & 1.87 & 2.85 & 5.14 & 8.31 & 9.94 & 9.26 & 6.71 & 4.80 & 2.74 & 4.732 \\
Model bias & ND & -0.20 & -0.25 & -0.32 & -0.23 & 0.05 & 0.36 & 0.75 & 0.55 & 0.28 & 0.38 & 0.37 & 0.17 & 0.159 \\
& DA & -0.13 & -0.15 & -0.14 & -0.13 & -0.09 & -0.07 & 0.22 & 0.08 & -0.05 & 0.05 & -0.04 & -0.09 & -0.045 \\
Model RMSD & ND & 0.82 & 0.87 & 0.86 & 0.87 & 1.15 & 1.62 & 1.65 & 1.53 & 1.30 & 1.07 & 1.08 & 1.10 & 1.16 \\
& DA & 0.49 & 0.51 & 0.48 & 0.58 & 0.73 & 1.15 & 1.02 & 0.82 & 0.72 & 0.70 & 0.73 & 0.81 & 0.728 \\
\hline
\end{tabular}

The unit for temperature is degrees Celsius. The mean is over the study area shown in Fig. 4

AR7W at 100-200 km, the model SSTs, both with and without data assimilation, have smaller errors than the satellite SST. The data assimilation combines the model and satellite SSTs to produce an improved SST.

The change in the model SST due to data assimilation is different from location to location and from season to season. From example, in spring, SSTs from the model with and without data assimilation for BON and FLC are very similar. This means that the correction term in the heat flux equation plays a minor role in the total heat flux. In contrast, the change of SST due to data assimilation is as large as $2.0^{\circ} \mathrm{C}$ in most sections in fall.

Another example is FLC which runs through the shallow shelf, the shelf break, and the Flemish Pass where the cold Labrador Current water is found in fall. Over the shelf, the correction term is large, forcing the model SST to approach the satellite SST. Over the Flemish Pass, however, the influence of the satellite SST becomes very weak. The flux correction plays a minor role there and the model SST is better than the satellite SST, although there is still a $2^{\circ} \mathrm{C}$ difference between the model and the in situ SST. Another region where significant errors in both the model and the satellite SSTs are found is near the end of SEC. Areas where neither satellite nor model gives good SSTs usually have high temperature gradients.

To quantify the skill of the data assimilation, we calculated the RMSD between the model/satellite SST and in situ SST using:

$R=\left[\frac{1}{N-1} \sum_{i=1}^{N}\left(T_{\mathrm{m} / \mathrm{c}}-T_{\mathrm{A}}\right)^{2}\right]^{1 / 2}$ where $N$ is the sample number, $T_{\mathrm{m} / \mathrm{c}}$ represents the SST from the model or satellite, and $T_{\mathrm{A}}$ is the in situ SST. We note that, because the SST variations across the sections are not statistically stationary, the means are not subtracted from the sample as in the standard statistical analysis. RMSD as defined by Eq. 11 includes both the errors of the mean and deviations from the mean.

RMSDs for the satellite SST and model SSTs with and without the data assimilation are given in Table 3. The data assimilation reduced the model error from $1.69^{\circ} \mathrm{C}$ to $1.06^{\circ} \mathrm{C}$. RMSD for the satellite SST, $1.29^{\circ} \mathrm{C}$, is smaller than the model RMSD without assimilation, but larger than that with assimilation. This suggests that model with data assimilation can provide the best estimate of the true SST.

For the assimilated SST, there is little difference between spring and fall. But the RMSD is smaller in spring for the satellite data and in fall for the model without assimilation.

\section{Sensitivity study}

The only unknown parameter in our assimilation scheme is $F^{\prime}$ in Eq. 9. This parameter is associated with the model and data errors and the diffusion depth. In the model runs discussed in the previous sections, $F^{\prime}$ was set to 0.1 . To investigate the sensitivity of the model results to $F^{\prime}$, we used a range of values for $F^{\prime}$ and computed the corresponding RMSDs. The result is shown in Fig. 6.

The curve $R$ has a minimum at $F^{\prime}=0.1$. We propose that this number represents the true mean value of $A$ / $\left[1+\left(\varepsilon_{\mathrm{o}} / \varepsilon_{\mathrm{m}}\right)^{2}\right] . R$ increases from $1.06^{\circ} \mathrm{C}$ to $1.69^{\circ} \mathrm{C}$ as $F^{\prime}$

Table 2 Monthly mean total heat flux from the model with (DA) and without (ND) data assimilation, difference between DA and ND, and the coefficient, $\gamma$, of the flux correction term in Eq. 5 for $t=t_{1}$

\begin{tabular}{|c|c|c|c|c|c|c|c|c|c|c|c|c|c|c|}
\hline & & Jan. & Feb. & March & April & May & June & July & Aug. & Sep. & Oct. & Nov. & Dec. & Mean \\
\hline \multirow[t]{2}{*}{ Heat flux $\left(\mathrm{W} \mathrm{m}^{-2}\right)$} & ND & 115 & 89 & 47 & -50 & -99 & -149 & -182 & -135 & -32 & 53 & 89 & 186 & -5.7 \\
\hline & DA & 107 & 90 & 40 & -36 & -86 & -136 & -185 & -134 & -35 & 67 & 93 & 179 & -3.0 \\
\hline $\mathrm{DA}-\mathrm{ND}$ & & -8 & 1 & -7 & 14 & 13 & 13 & -3 & 1 & -3 & 14 & 4 & -7 & 2.7 \\
\hline$\gamma\left(\mathrm{W} \mathrm{m}^{-2} \mathrm{~K}^{-1}\right)$ & & 530 & 534 & 539 & 379 & 228 & 150 & 123 & 141 & 201 & 283 & 273 & 461 & 329 \\
\hline
\end{tabular}

The mean is over the study area shown in Fig. 4 
Fig. 5 Comparison of SSTs from satellite and model SST with and without data assimilation $(D A)$ across the AZMP sections (see Fig. 1 for locations)
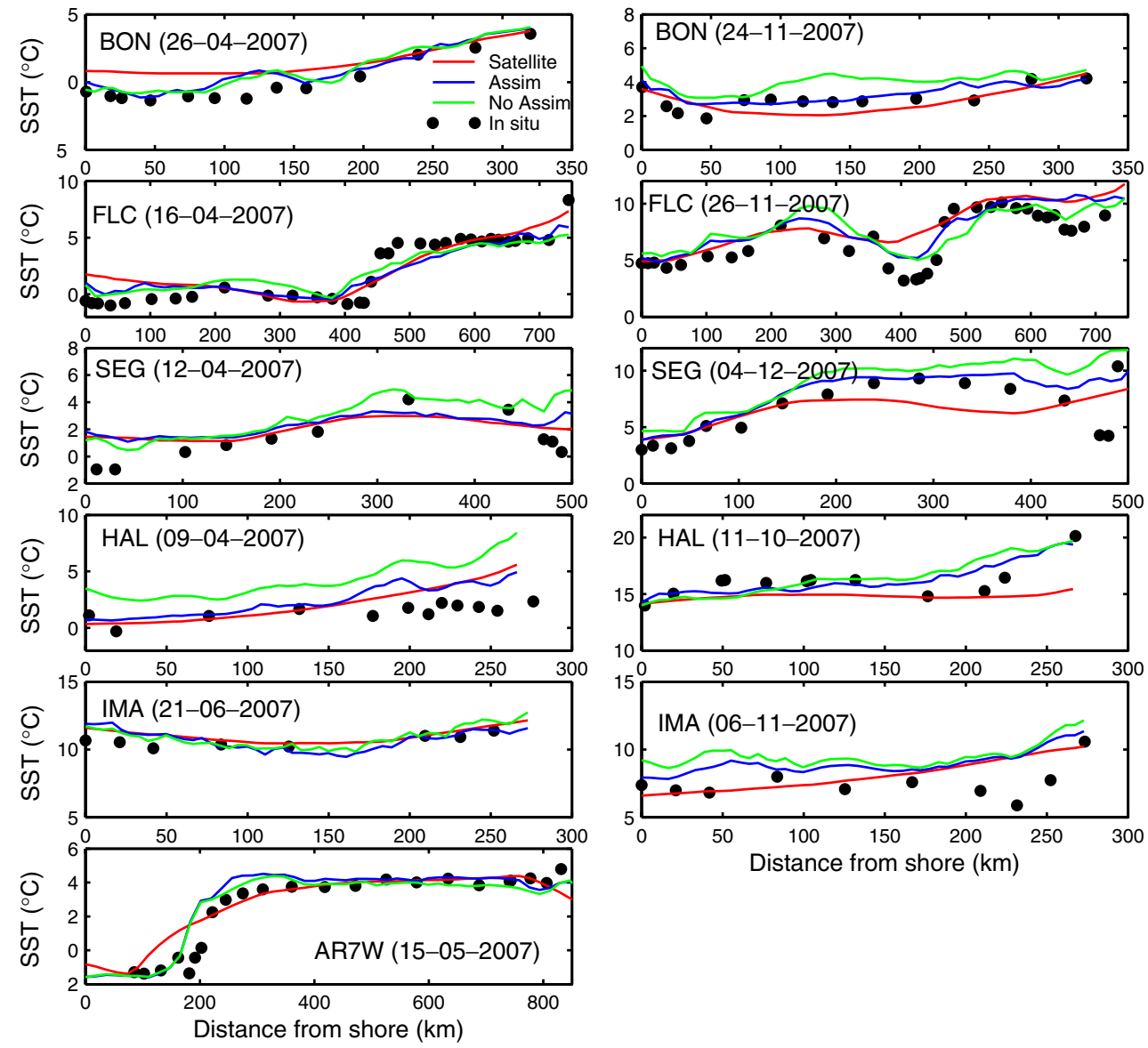

decreases from 0.1 to 0 . The reason for the larger RMSD at small $R$ is that the correction is too weak to correct the model SST. The assimilated SST is influenced more by the model dynamics than by the satellite data.

With the increase of $F^{\prime}$ from 0.1 to 0.2 , however, $R$ increases from $1.06^{\circ} \mathrm{C}$ to $1.40^{\circ} \mathrm{C}$. A large $F^{\prime}$ may cause overcorrection. The overcorrection may in turn lead to oscillation of the model SST. This usually occurs when the satellite SST is too high or too low. The temperature difference between the model and the satellite SST is then amplified by the high value of $F^{\prime}$.

$R$ is not very sensitive to $F^{\prime}$ around the optimal value $F^{\prime}=0.1$. A $20 \%$ increase of $F^{\prime}$ results in an $8.5 \%$ increase of $R$. In the range 0.06 to 0.16 , the model RSMD is smaller than the RSMD for the satellite data. This indicates over a large range of $F^{\prime}$, our assimilation gave better SST than the

Table 3 RMSD (in degrees Celsius) between model/satellite SST and ship SST

Spring Fall Combined spring

\begin{tabular}{llll}
\hline Satellite SST & 1.17 & 1.40 & 1.29 \\
Model (no assimilation) & 1.82 & 1.55 & 1.69 \\
Model (with assimilation) & 1.06 & 1.07 & 1.06 \\
\hline
\end{tabular}

satellite measurements. At $F^{\prime}=0.1$, the model RSMD is smaller than the satellite RSMD by $0.23^{\circ} \mathrm{C}$.

\section{Discussion}

The basic assumption of the flux correction method is that heat fluxes calculated from the bulk equations and atmospheric data are reasonably good, but an adjustment is needed to correct for errors in the fluxes from various sources. To gain an insight into the magnitude and

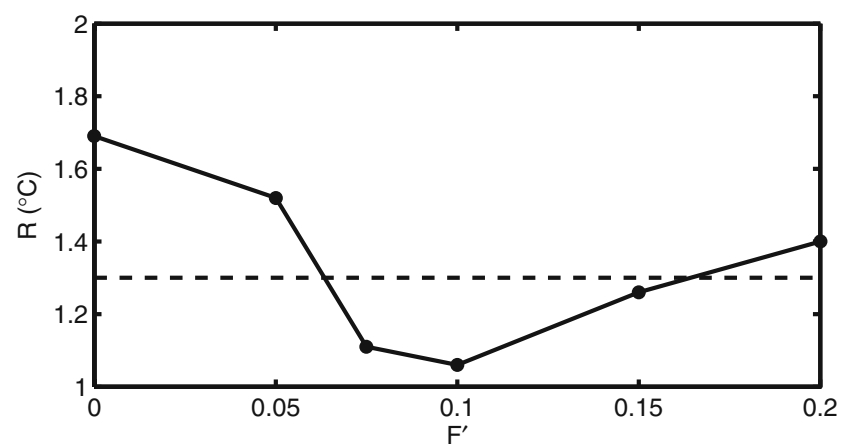

Fig. 6 Variation of RMSD between model and in situ SSTs with $F^{\prime}$. The horizontal dashed line is the RMSD for satellite SST 
Fig. 7 Time series of heat fluxes for the Scotia Shelf (see Fig. 1 for location) for $F^{\prime}=0$ (no data assimilation) and 0.1 . The bold lines represent total heat flux and the thin line represents heat flux correction for $F^{\prime}=0.1$

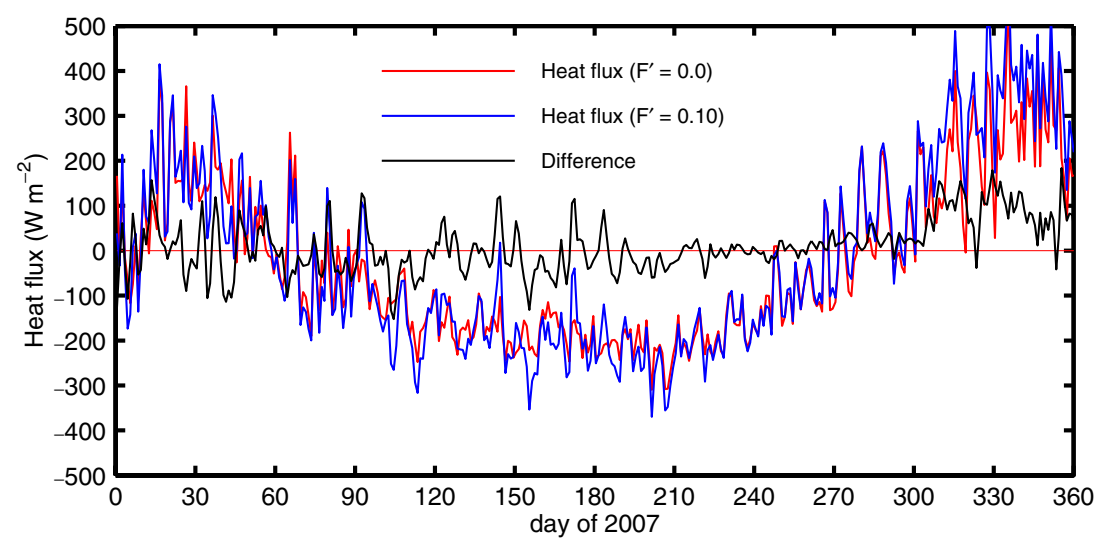

variability of the flux correction, daily averaged total heat flux, $Q^{\mathrm{a}}$ in Eq. 5, and the flux correction, the last term of Eq. 5, for the Scotia Shelf are shown in Fig. 7. The characteristics and general features of the heat flux correction at the other three locations are similar. Both the total flux and the flux correction are highly variable and change on several-day time scales. The instantaneous flux correction can be as large as the total flux, for example, at day 90 , but monthly or seasonally averaged values are in general smaller than the total flux. The flux corrections for the Scotia Shelf averaged over the seasons are 18, 15, -9, and $115 \mathrm{~W} \mathrm{~m}^{-2}$ for winter (January to March), spring, summer, and fall, respectively. In comparison, the corresponding total fluxes are 54, $-168,-173$, and 234 $\mathrm{W} \mathrm{m}{ }^{-2}$. The large flux correction in fall may be due to the low satellite SST. This can be seen from Fig. 5 and a comparison with other SST products. A low SST in fall results in a small ocean-to-air heat flux. A large positive heat flux is thus required to compensate for the small heat flux based on the satellite SST. Other possible causes include errors in wind speed and cloud cover that could lower the heat fluxes computed in the model. In most regions of the study area, a large flux correction is required to improve the SST in fall.

The mean total heat flux and the mean flux correction for August are shown in Fig. 8. The spatial distribution of the flux correction is far from uniform. The flux corrections are in the range $30-60 \mathrm{~W} \mathrm{~m}^{-2}$ over the Labrador Sea and around the mouth of Hudson Bay $\left(61^{\circ} \mathrm{N}, 65^{\circ} \mathrm{W}\right)$ and smaller, of the order of $20 \mathrm{~W} \mathrm{~m}^{-2}$, in the shelf regions. The variations in time and space of the flux correction suggest that using a constant coefficient in the flux correction method may lead to poor results.

\section{Conclusions}

SST from a near real-time operational product derived from satellite data has been assimilated into a coupled ice-ocean model for the Eastern Canada coastal waters, CECOM. The method of data assimilation is based on an optimal interpolation scheme by which the SST data are melded into the model through the adjustment of surface heat flux. The magnitude of the adjustment depends on the depth of
Fig. 8 Total heat flux (left) and the heat correction term (right) from the model run with data assimilation for August
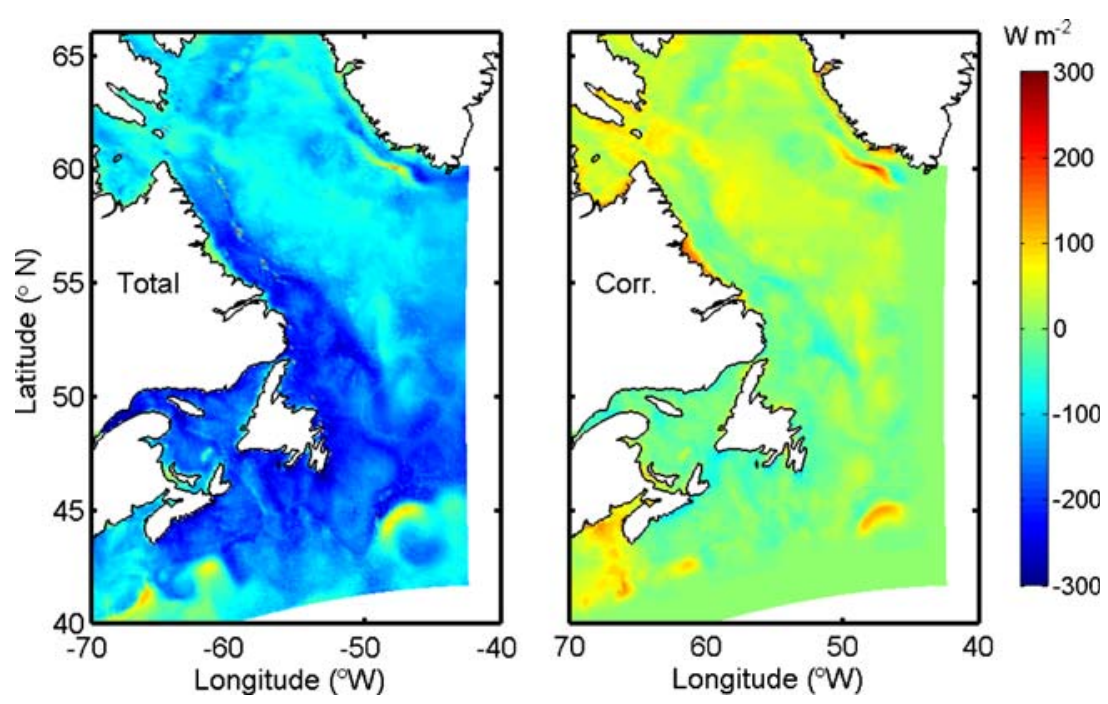
penetration of heat into the water column, the time scale of the satellite data, and the model and data errors. To evaluate the quality of the assimilation scheme, the satellite and model SSTs with and without assimilation are compared to an independent in situ data set. The comparisons indicate that the model uncertainties can be significantly reduced with data assimilation. The RMSD between the model SST and the in situ data is reduced from $1.69^{\circ} \mathrm{C}$ without assimilation to $1.06^{\circ} \mathrm{C}$ with assimilation. These numbers represent a $0.63^{\circ} \mathrm{C}$ or $37 \%$ reduction in error. The RMSD of the assimilated SST is also smaller than the RMSD of the satellite SST, $1.29^{\circ} \mathrm{C}$. This suggests that model simulations or predictions with data assimilation can provide the best estimate of the true SST.

The model error as measured by RMSD varies with an adjustable parameter in the flux correction term. There is an optimal value for the parameter corresponding to the minimum in the RMSD. The model SST is not very sensitive to the parameter around the minimum. A 20\% increase of the parameter value results in an $8.5 \%$ increase of RMSD.

The data assimilation method developed in this work does not only correct errors in the model and the total heat flux, but also errors in the satellite SST. The assimilated SST blends the satellite and model SSTs, giving an improved representation of the true SST. The application of the method, however, is limited to the upper ocean where ocean temperature is mainly controlled by air-sea fluxes and horizontal advection. In future studies, in order to assimilation temperature and other types of data at depth into the model, assimilation methods such as statistical projection (Ezer and Mellor 1994, 1997) should be considered.

Acknowledgements This research has been supported by the Canadian Program of Energy Research and Development. The satellite data were provided by the Canadian Meteorological Service. The AZMP data were provided by J. Spry, J. Higdon, and D. Senciall. We thank D. Greenberg for the helpful comments on the manuscript

Open Access This article is distributed under the terms of the Creative Commons Attribution Noncommercial License which permits any noncommercial use, distribution, and reproduction in any medium, provided the original author(s) and source are credited.

\section{References}

Aikman F III, Mellor GL, Ezer T, Sheinin D, Chen P, Breaker L, Bosley K, Rao DB (1996) Towards an operational nowcast/ forecast system for the U.S. East Coast. In: Malanotte-Rizzoli P (ed) Modern approaches to data assimilation in ocean modeling, vol 61. Amsterdam, Elsevier Oceanography Series, pp 347-376

Barnier B (1998) Forcing the ocean. In: Chassignet EP, Verron J (eds) Ocean modeling and parameterization. Kluwer Academic, The Netherlands, pp 45-80

Blumberg AF, Mellor GL (1987) A description of a three-dimensional coastal ocean circulation model. In: Heaps $\mathrm{N}$ (ed) Three- dimensional coastal ocean models, vol 4. American Geophysical Union, Washington, pp 1-16

Brasnett B (2008) The impact of satellite retrievals in a global seasurface-temperature analysis. Q J R Meteorol Soc 134:17451760. doi:10.1002/qj.319

Carton JA, Chepurin GC, Cao X (2000) A simple ocean data assimilation analysis of the global upper ocean 1950-95. Part I: methodology. J Phys Oceanogr 30:294-309

Covey C, AchutaRao KM, Cubasch U, Jones P, Lambert SJ, Mann ME, Phillips TJ, Karl E, Taylor KE (2003) An overview of results from the Coupled Model Intercomparison Project. Global Planet Change 37:103-133

Ezer T, Mellor GL (1992) A numerical study of the variability and the separation of the Gulf Stream, induced by surface atmospheric forcing and lateral boundary flows. J Phys Oceanogr 22:660 682

Ezer T, Mellor GL (1994) Continuous assimilation of Geosat altimeter data into a three-dimensional primitive equation Gulf Stream model. J Phys Oceanogr 24:832-847

Ezer T, Mellor GL (1997) Data assimilation experiment in the Gulf Stream region: how useful are satellite-derived surface data for nowcasting the subsurface fields? J Atmos Ocean Technol 14:1379-1391

Horton C, Schmitz J, Clifford M (1997) A real-time oceanographic nowcast/forecast system for the Mediterranean Sea. J Geophys Res 102:25123-25156

Kelley JGW, Behringer DW, Thiebaux HJ, Balasubramaniyan B (2002) Assimilation of SST into a real-time coastal ocean forecast system for the U.S. East Coast. Weather Forecast 17:670-690

Martinsen EA, Engedahl H (1987) Implementation and testing of a lateral boundary scheme as an open boundary condition in a barotropic ocean model. Coast Eng 11:603-627

Mellor GL, Ezer T (1991) A gulf stream and an altimetry assimilation scheme. J Geophys Res 96:8779-8795

Mellor GL, Häkkinen S, Ezer T, Patchen R (2002) A generalization of a sigma coordinate ocean model and an intercomparison of model vertical grids. In: Pinardi N, Woods J (eds) Ocean forecasting: conceptual basis and applications. Springer, Berlin, pp 55-72

Pinardi N, Rosati A, Pacanowski RC (1995) The sea surface pressure formulation of rigid lid models. Implications for altimetric data assimilation studies. J Mar Syst 6:109-119

Rochford PA, Kara AB, Wallcraft AJ, Arnone RA (2001) Importance of solar subsurface heating in ocean general circulation models. J Geophys Res 106:30923-30938

Tang CL (2007) High-resolution monthly temperature and salinity for the northwestern North Atlantic Ocean. Can Data Rep Hydrogr Ocean Sci 169:1-55, i-iv

Tang CL, Yao T, Perrie W, Detracey BM, Toulany B, Dunlap E, Wu Y (2008) BIO ice-ocean and wave forecasting models and systems for Eastern Canadian waters. Can Tech Rep Hydrogr Ocean Sci 261:1-61, i-iv

Wu YS, Tang CL, Sathyendranath S, Platt T (2007) The impact of biooptical heating on the properties of the upper ocean: a sensitivity study using a 3-D circulation model for the Labrador Sea. DeepSea Res II 54:2630-2642

Wu YS, Senciall D, Tang CL (2009) An evaluation of operational seasurface temperature analyses using AZMP data over the eastern Canadian shelves. AZMP Bull 8:35-39

Yao T, Tang CL, Peterson IK (2000) Modeling the seasonal variation of sea ice in the Labrador Sea with a coupled multicategory ice model and the Princeton ocean model. J Geophys Res 105:11531166 